\title{
Acute, Chronic and Fulminant Hepatitis E: Ten Years of Experience (2004-2013)
}

\author{
Maria Luisa Mateos Lindemann ${ }^{1}$, Maria Diez Aguilar ${ }^{1}$, Ana Gonzalez Galdamez ${ }^{1}$, Javier Graus Morales ${ }^{2}$, Ana Moreno \\ Zamora $^{3}$, Beatriz Suay Garcia ${ }^{4}$ and Maria Teresa Perez-Gracia ${ }^{4^{*}}$ \\ ${ }^{1}$ Servicio de Microbiologia. Hospital Universitario Ramon y Cajal. Madrid, Spain \\ ${ }^{2}$ Servicio de Gastroenterologia. Hospital Universitario Ramon y Cajal. Madrid, Spain \\ ${ }^{3}$ Servicio de Enfermedades Infecciosas. Hospital Universitario Ramón y Cajal, Madrid, Spain \\ ${ }^{4}$ Área de Microbiologia. Departamento Farmacia. Instituto Ciencias Biomédicas, Facultad de Ciencias de la Salud. Universidad CEU Cardenal \\ Herrera, Moncada, Valencia, Spain
}

\begin{abstract}
The hepatitis E virus (HEV) is the main cause of acute epidemic hepatitis in developing countries and it is estimated that approximately one third of the world's population has been infected with this virus. The aim of this study is to describe the most important clinical manifestations and epidemiological aspects in 62 hepatitis E cases treated in Madrid (Spain) during a 10-year period (2004-2013).

Fifty-five patients, six patients and one patient with acute, fulminant and chronic hepatitis E, respectively, have been studied over a period of 10 years. Sixty-two individuals ( 33 male and 10 female) were treated between 2004 and 2013 in the Hospital Ramón y Cajal (Madrid, Spain). The diagnosis was performed by the detection of IgG and IgM anti-HEV and HEV RNA in serum samples. Acute hepatitis E was defined by the presence of IgM anti-HEV and/or HEV RNA in serum and chronic hepatitis E if the RNA was detectable more than 6 months. Fulminant hepatitis $\mathrm{E}$ was diagnosed if encephalopathy was observed in addition to IgM anti-HEV and/or RNA HEV in serum. The median age was 46.67 and 49.6 years in acute hepatitis $\mathrm{E}$ and fulminant hepatitis $\mathrm{E}$, respectively. The risk factors recorded were travel to endemic areas in 14 patients, 4 were in contact with animals, 5 suffered from hepatic steatosis due to alcohol consumption, 3 consumed uncontrolled foods and 2 used to drink water from streams. HEV is the cause of acute self-limited hepatitis although $50 \%$ of the studied cases had to be hospitalized. However a small number of patients, $4.8 \%$ had fulminant hepatitis requiring hepatic transplant. Chronic hepatitis $\mathrm{E}$ is very infrequent in immunocompetent individuals. The increase in incidence of hepatitis $\mathrm{E}$ is due to better diagnostic tests in these recent years.
\end{abstract}

\section{Introduction}

The hepatitis E virus (HEV) is the main cause of acute epidemic hepatitis in developing countries and it is estimated that approximately one third of the world's population has been infected with this virus[1]. However, the epidemiological situation in developed countries is completely different. These countries have also reported cases of autochthonous acute hepatitis, chronic hepatitis and even fulminant hepatitis caused by HEV but in a low number of cases. It has been proved that HEV circulates in Spain [2] and the limited incidence of clinical manifestations is due to good hygienic conditions and an appropriate health-care structure. The prevalence of specific IgG type antibodies (anti-HEV IgG) in Spain varies depending on the type of population being studied; thus, $0.6 \%$ has been detected in individuals with no risk factors[3], 3.6\% in pregnant women[4], $18.6 \%$ in pig farm workers[5], and $10.11 \%$ in patients infected with HIV [6,7]. Other characteristics of the epidemiology in industrialized countries are that it affects older people, predominantly men and that the transmission route is generally unknown [8]. Its prevalence varies depending on the geographical region studied; accordingly, a high prevalence has been found in Catalonia (7.3\%)[9] in contrast with other areas of Spain such as Madrid and Valencia (2.8\% and $4 \%$ respectively) $[10,11]$. This might be due to the proximity of Catalonia to the south of France, where HEV appears to be hyperendemic having reported a very high prevalence (52\%) of anti-HEV IgG in blood donors [12]. The diagnosis is carried out by detecting anti-HEV IgG and IgM antibodies in blood with immunoenzymatic assays and the presence of HEV RNA in blood or feces using PCR. 4 genotypes of HEV are recognized, being genotype 3 responsible for practically all of the cases occurring in developed countries [13]. The most common

\section{Publication History:}

Received: May 21, 2014

Accepted: July 05, 2014

Published: July 07, 2014

Keywords:

Hepatitis E, HEV, Acute hepatitis, Fulminant hepatitis clinical manifestation is auto limited acute hepatitis, with an approximate duration of 4 to 6 weeks, with high concentrations of bilirubin and transaminases in serum. Some patients require hospitalization but most are discharged with home care after receiving treatment in the Emergency Department or by a Primary Attention doctor. However, very sever clinical manifestations with liver failure requiring a liver transplant may occur [14]. The purpose of this study is to describe the most important clinical manifestations and epidemiological aspects in 62 cases of hepatitis $\mathrm{E}$ treated at the Ramón y Cajal Hospital in Madrid (Spain) during a 10-year period (20042013).

\section{Materials and Methods}

From 2004 to 2013 we have studied 62 patients diagnosed with hepatitis E (acute, chronic or fulminant), treated in the Emergency,

"Corresponding Author: Dr. Maria Teresa Perez-Gracia, Area de Microbiología Departamento Farmacia. Instituto Ciencias Biomédicas, Facultad de Ciencias de la Salud. Universidad CEU Cardenal Herrera, Moncada, Valencia, España.; E-mail: teresa@uch.ceu.es

Citation: Lindemann MLM, Aguilar MD, Galdamez AG, Morales JG, Zamora AM, et al. (2014) Acute, Chronic and Fulminant Hepatitis E: Ten Years of Experience (2004-2013). Int J Gastroenterol Disord Ther 1: 102. doi: http:// dx.doi.org/10.15344/2393-8498/2014/102

Copyright: () 2014 Lindemann et al. This is an open-access article distributed under the terms of the Creative Commons Attribution License, which permits unrestricted use, distribution, and reproduction in any medium, provided the original author and source are credited. 
Citation: Mateos Lindemann MLM, Aguilar MD, Galdamez AG, Morales JG, Zamora AM, et al. (2014)Acute, Chronic and Fulminant Hepatitis E: Ten Years of Experience (2004-2013). Int J Gastroenterol Disord Ther 1: 102. DOI: http://dx.doi.org/10.15344/2393-8498/2014/102

Infectious Diseases and Gastroenterology Services of the Ramón y Cajal Hospital (Madrid). The diagnosis of hepatitis E was carried out by the detection of anti-HEV IgG and/or IgM antibodies using enzyme-linked immunosorbent assays (Bioelisa HEV IgG and Bioelisa IgM, Biokit, Barcelona, Spain) confirming the positive results with Western blot (RecomBlot HEV IgG/IgM; Mikrogen, Martinsried, Germany). In 42 of the sera it was possible to continue the study to detect HEV RNA using non-commercial PCR in serum [15]. In 20 of the patients the detection of HEV RNA was not possible because there was not enough blood samples. All the samples positive for HEV RNA were sequenced (ABI PRISM 310). The sequence alignment was carried out using ClustalW and the Lasergene Segman software was used for the analysis of the sequences [16]. Feces were not collected from patients. The acute hepatitis $\mathrm{E}$ diagnosis was considered when the patient presented clinical manifestations compatible with acute hepatitis and anti-HEV IgM and or HEV RNA were detected in serum along with anti-HEV IgG in the same or subsequent samples. The chronic hepatitis $\mathrm{E}$ was defined by the presence of HEV RNA in serum for a period longer than 6 months along with an increase in transaminases levels. Fulminant hepatic failure (FHF) was diagnosed when a severe deterioration of the hepatic function was observed associated to encephalopathy in the presence of anti-HEV IgM and/ or HEV RNA in serum.

The protocol of this study included the collection of the following variables in the moment hepatitis $\mathrm{E}$ was diagnosed: gender, age, risk factors (having travelled to endemic areas, consumption of uncontrolled food, contact with animals and/or alcohol consumption), home observation or hospitalization, common hepatic tests (bilirubin serum concentration, alanine and aspartate aminotransferases, prothrombin activity and cephalin time, plasmatic fibrinogen concentration) and evaluation of the co-infection with other hepatotropic viruses (HAV, HBV, HCV, CMV, EBV).

The detection of serological markers for viral hepatitis different from hepatitis E was carried out in the first blood sample obtained at the hospital with the automatic system AXSYM and again later with Architect (Abbott Diagnostics, Chicago, USA). The following markers were studied: surface antigen of the hepatitis B virus (HBV), antibodies against the core antigen of $\mathrm{HBV}$, antibodies against the hepatitis $\mathrm{C}$ virus (HCV), IgG and IgM antibiodies against the hepatitis A virus (HAV), IgG and IgM antibodies against cytomegalovirus (CMV) and Epstein Barr virus (EBV). HBV DNA and HCV RNA were also evaluated using real time PCR (Tagman, Roche Diagnostics, Plesanton, USA) in patients with positive results for surface HBV antigens or HCV antibodies respectively. The presence of antinuclear antibodies (ANA, ASMA, AMA, and LKM) was determined in selected cases. Hepatic biopsy was only practiced in the patient for whom chronic hepatitis was suspected. The values of the different quantitative variables are expressed as a median or as an absolute number (percentage) where appropriate.

\section{Results}

The sample is made up of 62 patients ( 43 men and 19 women) (Table 1). Fifty-five (41 men and 14 women) presented clinical manifestations compatible with acute hepatitis; in one male patient chronic hepatitis was diagnosed and 5 ( 4 women and 2 men) debuted with fulminant liver failure, with 4 of them requiring hepatic transplant (Table 1).

The average age of the patients with acute hepatitis was 46.7 years old and 49.6 for those with fulminant hepatitis. The only patient with chronic hepatitis was 72 years old.

Among the epidemiologic background of interest, 14 of them had travelled to endemic areas (India, Nepal, Egypt, Angola, Ecuador, Brazil, Dominican Republic, Morocco, Cuba, Mexico and Peru), 4 had contact with animals (butcher, slaughterer, veterinarian and regular horseback rider), 3 consumed herbalist products regularly and 2 drank water from streams. The remaining 48 patients did not refer any activity or epidemiologic risk factors related with $\mathrm{HEV}$ infection. Pregnancy was discarded in women in childbearing age.

The serum concentrations of bilirubin, ALT and AST are shown in Table 1 .

\begin{tabular}{|c|c|c|c|}
\hline & $\begin{array}{l}\text { Acute hepatitis } \\
\text { (n: 55) }\end{array}$ & $\begin{array}{l}\text { Fulminant } \\
\text { hepatitis } \\
\text { (n: 6) }\end{array}$ & $\begin{array}{l}\text { Chronic } \\
\text { hepatitis (n: 1) }\end{array}$ \\
\hline $\begin{array}{l}\text { Age } \\
(\text { mean } \pm S D)\end{array}$ & $46.67 \pm 15.03$ & $49.6 \pm 17.16$ & 72 \\
\hline Gender (M/F) & $41 / 14$ & $1 / 5$ & $1 / 0$ \\
\hline $\begin{array}{l}\text { Bilirubin } \\
\text { (UI/L) }\end{array}$ & $\begin{array}{l}7.71(0.36- \\
27.5)\end{array}$ & $\begin{array}{l}10.25(1.89- \\
26)\end{array}$ & 25 \\
\hline ALT (UI/L) & $\begin{array}{l}1653.08(141- \\
4148)\end{array}$ & $\begin{array}{l}2043.75 \\
(1426-2820) \\
\end{array}$ & 1118 \\
\hline AST (UI/L) & $\begin{array}{l}1258.19(45- \\
4950)\end{array}$ & $\begin{array}{l}1391(387- \\
2429)\end{array}$ & 1122 \\
\hline $\begin{array}{l}\text { Risk factors } \\
\text { Travels } \\
\text { Animals } \\
\text { Untreated } \\
\text { water or food } \\
\text { Immigrant } \\
\text { Alcohol } \\
\mathrm{NR}^{*}\end{array}$ & \begin{tabular}{|l}
14 \\
4 \\
5 \\
\\
4 \\
3 \\
15
\end{tabular} & $\begin{array}{l}0 \\
0 \\
0 \\
0 \\
2 \\
0\end{array}$ & $\begin{array}{l}0 \\
0 \\
0 \\
0 \\
0 \\
1\end{array}$ \\
\hline Trasplant & 0 & 3 & 0 \\
\hline $\begin{array}{c}\text { Coinfections } \\
\text { HAV } \\
\text { HBV } \\
\text { HCV } \\
\text { HIV }\end{array}$ & $\begin{array}{l}\text { Yes } \\
2 \\
5 \\
6 \\
1\end{array}$ & No & No \\
\hline
\end{tabular}

Table 1: Characteristics of the acute, fulminant and chronic hepatitis caused by HEV.

It must be noted that both anti-HEV IgG and IgM were detected in all the patients included in the present study. The HEV RNA was studied in 42 serum samples, obtaining positive results in 17 (40.4\%). It was possible to study the presence of HEV RNA in 32 of the 55 patients with acute hepatitis, being positive in 11 (34.3\%) cases. In all patients with fulminant hepatitis and in the case of chronic hepatitis HEV RNA was detected in the first blood sample taken upon admission. The genotype $3 \mathrm{f}$ was found in all the samples.

Thirteen patients presented co-infection with other hepatotropic viruses: in 2 of them acute infection with HAV was diagnosed 
concomitantly, 6 had a chronic infection with HCV and 5 presented chronic hepatitis B. The bilirubin, ALT and AST levels in these patients did not show a relevant difference when compared to those of patients only infected with HEV. One patient was infected with the HIV and was receiving antiretroviral treatment. In 2 of the 6 patients with fulminant hepatitis, hepatic steatosis related to alcohol consumption was evidenced.

In the hepatic biopsy practiced in the cases in which chronic hepatitis $\mathrm{E}$ was suspected, histologic alterations of chronic hepatitis with moderate signs of necroinflammatory activity and level III/IV fibrosis were detected (METAVIR score).

\section{Discussion}

HEV may cause a wide range of hepatic clinical symptoms both in endemic and in nonendemic countries. Genotype 3 of the HEV is characteristic in non-endemic countries and it is the only one isolated so far in autochthonous cases in our country $[17,18]$. It has been confirmed that the prevalence of HEV infection has not increased in Spain in recent years regardless of the frequent travelling and immigration [4]. This may be due to the good health-care structure in our country. However, the increase in incidence is due to a better understanding of the disease and to the easiness with which it can be diagnosed in most hospitals [19].

Being in direct contact with animals is a proven risk factor because the infection with genotype 3 of the HEV is considered a zoonosis that primarily affects swine, but also other animals [20,21]. In our study, we found this precedent in 4 patients. Among the considered risk factors, it is noteworthy that three individuals consumed uncontrolled herbalist products regularly and two drank water from streams regularly. It was not possible to conduct an epidemiologic investigation, but the acquisition of the HEV could have taken place through these products.

It is important to consider that the meat and pork product consumption in Spain is widespread and it could have been the transmission route in many of the cases in which no risk factors were identified. Due to the long incubation period, the potentially implicated foods were not available for testing. Nevertheless, HEV has been detected in the leftovers of the consumed pork meat in Barcelona, proving the zoonotic transmission [22]. In four of the patients, alcohol consumption favored the onset of hepatic symptoms because steatosis or hepatic fibrosis conditioned a more severe response from the host. Other authors have confirmed this fact previously, with hepatic steatosis being currently considered a risk factor [23].

Most infections produced by the genotype 3 of HEV are asymptomatic or anicteric, which explains the high rate of antiHEV IgG antibodies found in the general population and the low incidence of clinic hepatic disease diagnosed in Spain [24]. However, HEV infection in some individuals can lead to fulminant liver failure, requiring a liver transplant. In our study, 6 of the $62(9.7 \%)$ cases evolved to fulminant hepatitis. Nonetheless, it must be noted that this rate is biased due to selection-derivation to a tertiary center.

Out of the 6 patients with fulminant hepatitis, 3 of them ( 2 women and a man) required liver transplant. Two of these patients (a woman and a man) had hepatic steatosis due to alcohol consumption. Other authors have also proved that HEV superinfection in patients with chronic liver disease of a different etiology may cause an important increase in transaminase levels and liver failure (acute or chronic hepatitis)[25]. A woman with fulminant hepatitis was taking oral contraceptives during a very long period of time and this has been considered a predisposing factor [26]; this patient was the only one that did not require a transplant because her evolution was satisfactory. No risk factors for HEV infection were detected in the other patients with fulminant liver failure.

It must be noted that, in an immunocompetent patient, the acute hepatitis $\mathrm{E}$ evolved to chronic hepatitis in a period of one year and six months, with stage III/IV fibrosis in the liver biopsy and detection of anti-HEV IgM and HEV RNA in blood during more than 6 months. The evolution has been good even though the patient rejected ribavirin treatment. Up to now, chronic liver disease due to HEV had only been described in immunocompromised patients such as transplant recipients, patients with malign hematologic diseases or receiving chemotherapy, infected with $\operatorname{HIV}[27,28]$, autoimmune diseases treated with corticoids and immunosupressors, among others. However, in the face of this case and another one that has been recently described [29] the fact that HEV may also become chronic in immunocompetent patients must be considered along with the idea that some of the chronic liver diseases and cirrhosis that are currently considered idiopathic could be related to a previous infection with HEV that could have gone unnoticed. Nonetheless, we still do not have enough proof to recommend HEV RNA detection in the serum of all the cirrhosis with unknown cause in immunocompetent individuals [30] having in mind that this technique is not available in most laboratories.

HEV RNA detection in serum can be considered the most important virological marker in this infection, although it has a limited value in acute hepatitis due to the briefness of the viremia (about 2 weeks) and the excretion in feces in a way that might be negative when the patient requires hospitalization [31]. For this reason, its absence does not allow the diagnosis of acute HEV infection to be discarded. For this matter, the detection of anti-HEV IgM antibodies constitutes an appropriate marker for the diagnosis of acute infection since they appear during the acute phase of the disease (during the final moments of incubation or at the onset of jaundice), and remain detectable for 4-5 months [32]. It must be noted that, regardless of the low sensibility in the determination of HEV RNA in acute hepatitis, it was detectable in all the cases of fulminant hepatitis and chronic hepatitis with HEV.

Our study has several limitations. Only patients with a diagnosis of hepatitis $\mathrm{E}$ under very strict laboratory criteria have been included. For example, those who presented positive anti-HEV IgM but seroconversion (anti-HEV IgG) could not be demonstrated were not considered hepatitis E even though they had compatible symptoms. Moreover, the high number of fulminant hepatitis detected in our study is due to the transfer from other hospitals in which liver transplants are not practiced, to ours. Lastly, in Spain, only patients with conspicuous symptoms are treated in hospitals, while those with mild symptoms are treated by general practicioners in primary attention centers.

In conclusion, we have analyzed the clinical manifestations and epidemiologic factors of a series of 62 patients diagnosed with hepatitis $\mathrm{E}$, a disease that is not very frequent in our country at the moment, but can be easily diagnosed if the differential diagnosis is 
Citation: Lindemann MLM, Aguilar MD, Galdamez AG, Morales JG, Zamora AM, et al. (2014)Acute, Chronic and Fulminant Hepatitis E: Ten Years of Experience (2004-2013). Int J Gastroenterol Disord Ther 1: 102. DOI: http://dx.doi.org/10.15344/2393-8498/2014/102

Page 4 of 4

taken into account. It is important to consider the diagnosis of hepatitis $\mathrm{E}$ in acute hepatitis with negative hepatitis $\mathrm{A}, \mathrm{B}$ and $\mathrm{C}$ markers, especially if there is an interesting epidemiologic factor such as travels, having been in contact with animals and/or consumption of uncontrolled food and water; furthermore, it must be included in the differential diagnosis of fulminant liver failures with or without previous liver disease and in other cases such as that of patients with unrelated chronic liver disease, autoimmune or drug-induced hepatitis[14] (Table 2).

\begin{tabular}{|l|}
\hline Acute hepatitis with negative markers for hepatitis A, B and C \\
\hline $\begin{array}{l}\text { Acute hepatitis with any risk factors (travel to endemic } \\
\text { areas, contact with animals, "unusual" food consumption...) } \\
\text { independently of other markers of viral hepatitis }\end{array}$ \\
\hline Liver failure or decomposition in chronic liver disease \\
\hline Drug-induced hepatitis \\
\hline Autoimmune hepatitis \\
\hline $\begin{array}{l}\text { Chronic liver disease of unknown etiology in immune } \\
\text { compromised patients }\end{array}$ \\
\hline
\end{tabular}

Table 2: Clinical situations should be suspected hepatitis E (request IgG anti-HEV, IgM anti-HEV and /or HEV RNA).

\section{Acknowledgement}

This study has been partially financed through the aids granted by the Universidad CEU Cardenal Herrera (PRUCH 25/10, PRUCH 39/11 and Santander-PRUCH 19/12).

\section{References}

1. Who. Viral Hepatitis Statement A62/22.

2. Pina S, Jofre J, Emerson SU, Purcell RH, Girones R (1998) Characterization of a strain of infectious hepatitis $E$ virus isolated from sewage in an area where hepatitis $E$ is not endemic. Appl Environ Microbiol 11: 4485-4488.

3. Suarez Gonzalez A, Solıs Sanchez G, Otero Guerra L, Viejo de la Guerra G Alvarez Navascues C, et al. (2004) Prevalencia de inmunidad frente a los virus de la hepatitis en gestantes del Area Sanitaria de Gijon. Gastroenterol Hepato 27: 347-352.

4. Lindemann ML, Gabilondo G, Romero B, de la Maza OM, Pérez-Gracia MT (2010) Low prevalence of hepatitis $E$ infection among pregnant women in Madrid, Spain. J Med Virol 82: 1666-1668.

5. Galiana C, Fernandez-Barredo S, Garcıa A, Gomez MT, Perez-Gracia MT (2008) Occupational exposure to hepatitis E virus (HEV) in swine workers. Am J Trop Med Hyg 78: 1012-1015.

6. Mateos-Lindemann ML, Gonzalez-Galdámez A, Bordallo-Cardona M, Pérez Gracia MT (2012) Are HIV-infected patients a high-risk population for hepatitis E virus infection in Spain? Enferm Infecc Microbiol Clin 30: 582-583.

7. Mateos-Lindemann ML, Diez-Aguilar M, Galdamez AL, Galán JC, Moreno A, e al. (2014) Patients infected with HIV are at high-risk for hepatitis $E$ virus infection in Spain. J Med Virol 86:71-74.

8. Pérez-Gracia MT, Suay B, Mateos-Lindemann ML (2014) Hepatitis E: an emerging disease. Infect Genet Evol 22: 40-59.

9. Buti M, Domínguez A, Plans P, Jardí $R$, Schaper $M$, et al. (2006) Communitybased seroepidemiological survey of hepatitis $E$ virus infection in Catalonia, Spain. Clin Vaccine Immunol 13:1328-1332.

10. Mateos ML, Camarero C, Lasa E, Teruel JL, Mir N, et al. (1999) Hepatitis E virus: relevance in blood donors and risk groups. Vox Sang 76: 78-80.

11. Galiana C, Fernández-Barredo S, Pérez-Gracia MT (2010) Prevalencia del virus de la hepatitis $E(V H E)$ and risk factors in pig workers and blood donors. Enferm Infecc Microbiol Clin 28: 602-607.
12. Mansuy JM, Bendall R, Legrand-Abravanel F, Sauné K, Miédouge M, et al. (2011) Hepatitis E virus antibodies in blood donors, France. Emerg Infect Dis 17 2309-2312.

13. Pérez-Gracia MT, Mateos Lindemann ML, Caridad Montalvo Villalba $M$ (2013) Hepatitis E: current status. Rev. Med. Virol 23: 384-398.

14. Kamar N, Legrand-Abravanel F, Izopet J, Rostaing L (2012) Hepatitis E Virus: What Transplant Physicians Should Know. Am J Transplant 12: 2281-2287.

15. Fernández-Barredo S, Galiana C, Garcia A, Vega S, Gómez MT, et al. (2006) Detection of hepatitis $E$ virus shedding in feces of pigs at different stages of production using reverse transcription-polymerase chain reaction. $\mathrm{J}$ Vet Diag Invest 18: 462-465.

16. Kumar S, Tamura K, Nei M (2004) MEGA3: Integrated software for Molecular Evolutionary Genetics Analysis and sequence alignment. Brief Bioinform 5: 150 163.

17. Pérez-Gracia MT, Mateos ML, Galiana C, Fernández-Barredo S, García A, et al. (2007) Autochthonous hepatitis $E$ infection in a slaughterhouse worker. Am J Trop Med Hyg 77: 893-896.

18. Mateos-Lindemann ML, Diez-Aguilar M, González-Galdamez A, GrausMorales J, Moreno-Zamora A, et al. (2013) Hepatitis E agudas, crónicas y fulminantes: siete años de experiencia (2004-2011). Enferm. Infecc. Microbio Clin 31: 595-598

19. Pérez-Gracia MT, Mateos-Lindemann ML (2012) Estado actual de la hepatitis E. Med Clin (Barc). 139: 404-411.

20. Fernández-Barredo S, Galiana C, García A, Gómez-Muñoz MT, Vega S, et al. (2007) Prevalence and genetic characterization of hepatitis $E$ virus in paired samples of feces and serum from naturally infected pigs. Can $J$ Vet Res 71 : 236-240.

21. García M, Fernández-Barredo S, Pérez-Gracia MT (2014) Detection of hepatitis $E$ virus (HEV) through the different stages of pig manure composting plants. Microb Biotechnol 7: 26-31.

22. Riveiro-Barciela M, Minguez B, Girones $R$, Rodriguez-Frias F, Quer J, et al. (2014) Phylogenetic demonstration of hepatitis $E$ infection transmitted by pork meat ingestion. J Clin Gastroenterol.

23. Dalton HR, Bendall RP, Rashid M, Ellis V, Ali R, et al. (2011) Host risk factors and autochthonous hepatitis E infection. Eur J Gastroenterol y Hepatol 23: 12001205.

24. Riveiro-Barciela M, Rodríguez Frías F, Buti M (2012) Hepatitis E: scale of the problem in Spain. Gastroenterol Hepatol. 35: 719-724.

25. Dalton H (2012) Hepatitis $E$ and decompensated chronic liver disease. Nat Rev Gastroenterol Hepatol 9: 430-432.

26. Mateos Lindemann ML, Graus Morales J, Fernández Barredo S, Rodríguez Domínguez M, García de la Hoz F, et al. (2010) Fulminant Hepatitis E in a woman taking oral contraceptive medication. Am J Trop Med Hyg 82: 12-15.

27. Kamar N, Selves J, Mansuy JM, Ouezzani L, Peron JM, et al. (2008) Hepatitis $\mathrm{E}$ virus and chronic hepatitis in organ-transplant recipients. N Engl J Med 358: 811-817.

28. Le Coutre P, Meisel H, Hofmann J, Röcken C, Vuong GL, et al. (2009) Reactivation of hepatitis $E$ infection in a patient with acute lymphoblastic leukaemia after allogeneic stem cell transplantation. Gut 58: 699-702.

29. Grewal P, Kamili S, Motamed D (2014) Chronic hepatitis E in an immunocompetent patient. A case report. Hepatology 59: 347-348.

30. González Tallón A, Moreira V, Mateos Lindemann ML (2012) Chronic hepatitis E. Med Clin (Barc) 138: 69-72.

31. Aggarwal R (2013) Diagnosis of hepatitis E. Nat Rev Gastroentrol Hepatol 10: $24-33$

32. Khudyakov Y, Kamili S (2011) Serological dianostics of hepatitis E virus infection. Virus Res 161: 84-92.
Int J Gastroenterol Disord Ther

ISSN: $2393-849$
IJGDT, an open access journal Volume 1.2014. 102 